
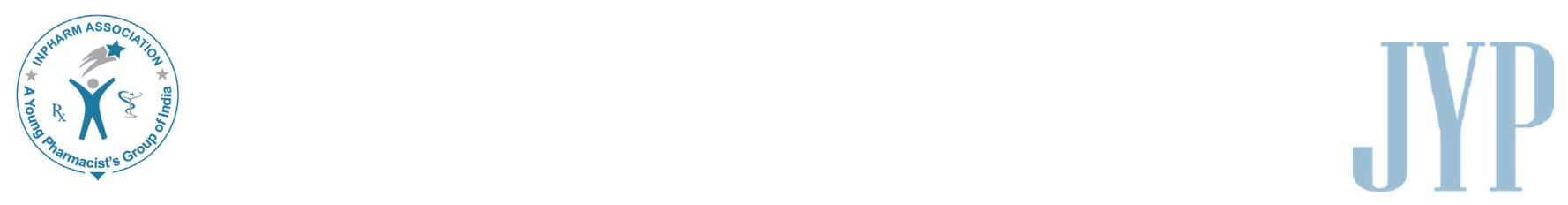

\title{
Assessment of different biological capacities of Alpinia speciosa (Pers.) B.L. Burtt and R.M. Sm
}

\author{
Rebeca Mól Lima', Hudson Caetano Polonini'1, Kauana Cristina de Souza', \\ Marcos Antônio Fernandes Brandão1, Ivone Salgado² and Nádia Rezende \\ Barbosa Raposo ${ }^{1, *}$
}

${ }^{I}$ Núcleo de Pesquisa e Inovação em Ciências da Saúde (NUPICS), Universidade Federal de Juiz de Fora, Brazil.

${ }^{2}$ Núcleo de Pesquisa e Inovação Tecnológica (NUPITE), Universidade Federal de Juiz de Fora, Brazil.

\begin{abstract}
Objective: The present study was undertaken to evaluate antioxidant, depigmenting and photoprotective activities of the hydroalcoholic extract of Alpinia speciosa leaves. Methods: In vitro spectrophotometric methods were used to determine the total phenolic and flavonoids contents and the above mentioned biological capacities. Results: The antioxidant activity for the hydroalcoholic extract of $A$. speciosa showed a very good result $\left(\mathrm{IC}_{50}=7.13 \mu \mathrm{g} \mathrm{mL}^{-1}\right.$, statistically different from the ascorbic acid reference standard at $p<0.05$ ), which can be elucidated by their content of phenolic compounds, such as flavonoids. As for the depigmenting activity, the tyrosinase inhibitory ability demonstrated that the $A$. speciosa presented IA\% lower than $50 \%$, but it also presented a better stability than kojic acid standard. The extract also presented a significant photoprotection for a single UV-filter substance (SPF, UVAPF, Critical Wavelength and UVA/UVB Ratio), and it can be considered a broad-spectrum filter. Conclusion: These data altogether indicate that $A$. speciosa can have application in cosmeceuticals for aesthetics or degenerative diseases.
\end{abstract}

Key words: Alpinia speciosa, Antioxidant, Depigmentant, Flavonoids content, Photoprotection, Total phenolic content.

\section{INTRODUCTION}

Alpinia speciosa (Pers.) B.L. Burtt and R.M. Sm. (Family Zingiberaceae), also known as Alpinia zerumbet, is a worldwide distributed edible and medicinal plant that grows mainly in subtropical and tropical areas. Popularly known as

\begin{tabular}{|c|c|}
\hline \multicolumn{2}{|c|}{ Access this article online } \\
\hline Journal Sponsor & \multirow[b]{2}{*}{$\begin{array}{l}\text { Website: } \\
\text { www.jyoungpharm.org }\end{array}$} \\
\hline \multirow{2}{*}{ www.phcog net } & \\
\hline & $\begin{array}{l}\text { DOI: } \\
\text { 10.5530/jyp.2015.4s.13 }\end{array}$ \\
\hline
\end{tabular}

Colônia and Pacova, it was probably originated somewhere in tropical Asia. ${ }^{1}$ Used as food and herbal medicine, the leaves of A. speciosa have already some pharmacological effects described in literature: for skin care, insect repellent and deodorant products, ${ }^{2}$ as hypotensive, diuretic and antiulcerogenic, ${ }^{3}$ and also possessing antinociceptive effects on mice ${ }^{4}$ and antihypertensive and cardiovascular effects on rat. ${ }^{5}$ More recently studies reported the high phenolic content of $A$. speciosa. ${ }^{1,6}$ However, to the best of the author's knowledge there is no previous report linking the photoprotective and skin whitening activities of this species.

*Address for correspondence:

Dr. Nádia Rezende Barbosa Raposo, Núcleo de Pesquisa e Inovação em Ciências da Saúde (NUPICS), UFJF, Rua José Lourenço Kelmer, s/n, Campus Universitário, CEP 36036-900, Juiz de Fora, MG, Brazil.E-mail:nadiafox@gmail.com 

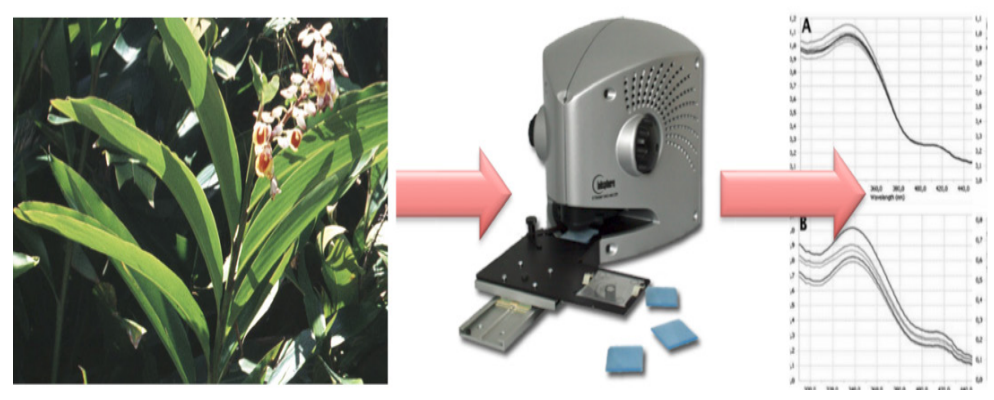

Graphical Abstract

Considering all these aspects, the present study was undertaken to evaluate antioxidant, depigmenting and photoprotective activities of the hydroalcoholic extract of leaves of $A$. speciosa, as well as its total phenolic and flavonoid contents.

\section{MATERIALS AND METHODS}

\section{Plant material}

The plant was collect at the UFJF's Faculty of Pharmacy's Garden (Atlantic Forest Biome, Brazil). Dr Fátima Salimena identified the species and the exsiccate was deposited in the Herbarium Leopoldo Krieger. Specimens' leaves (50 g) were cleaned with water and dried in a circulating air oven $\left(21^{\circ} \mathrm{C}\right.$, four days). Subsequently, the material was ground in a knife mill (TA-2, Metvisa, Brazil) and statically macerated in ethanol for three days at room temperature. The filtrates were subjected to slowly rotary evaporator (R-114-Buchi, Switzerland) under reduced pressure at $40^{\circ} \mathrm{C}$ until the complete removal of the solvent. The material was stored protected from light in air-tight containers at $-20^{\circ} \mathrm{C}$ until its use.

\section{Antioxidant Activity}

The antioxidant activity was evaluated using the 2,2-diphenyl-1-picrylhydrazyl (DPPH; Sigma-Aldrich, USA) assay. An aliquot of $150 \mu \mathrm{L}$ of a $0.05 \mathrm{mM}$ ethanolic DPPH was added to $50 \mu \mathrm{L}$ of ethanolic solution of the extract at concentrations from 0.97 to $250 \mu \mathrm{g} \mathrm{mL} \mathrm{L}^{-1}$ in 96-well plates. Ascorbic acid was used as standard at the same concentrations. Reactions elapsed at room temperature for 30 minutes in the dark and then the absorbance was read in a spectrophotometer $(\lambda=510$ $\mathrm{nm})$. Inhibition of DPPH radical was calculated using the equation $\mathrm{IC}_{\%}=[(C-S) / C] \times 100$, being $\mathrm{IC}=$ Inhibitory activity, $C=$ absorbance of the negative control, and $S=$ absorbance of the test samples. The $\mathrm{IC}_{50}$ was calculated from the equation of the linear dispersion graph. All tests were performed in triplicate.

\section{Tyrosinase inhibition enzymatic assay}

Aliquots of $10 \mu \mathrm{L}$ of a solution composed by $125 \mathrm{U} \mathrm{mL}^{-1}$ of mushrooms tyrosinase (Sigma-Aldrich, USA) were added to 96-well microplates, and then $70 \mu \mathrm{L}$ of $\mathrm{pH} 6.8$ phosphate buffer solution and $60 \mu \mathrm{L}$ of the extract $(350 \mu \mathrm{g}$ $\mathrm{mL}^{-1}$, in $25 \%$ dimethyl sulfoxide-DMSO) were also added. For the positive control, $60 \mu \mathrm{L}$ of kojic acid $\left(17.5 \mu \mathrm{g} \mathrm{mL}^{-1}\right.$ in $25 \%$ DMSO) was used instead of the extract, and for the negative control $60 \mu \mathrm{L}$ of $25 \% \mathrm{DMSO}$ were added. To the resultant mixture, $70 \mu \mathrm{L}$ of aqueous L-tyrosine $(0.3 \mathrm{mg}$ $\mathrm{mL}^{-1}$ ) (Sigma-Aldrich, USA) were added (final volume $=210$ $\mu \mathrm{L}$ ). The absorbances were read at $510 \mathrm{~nm}\left(\mathrm{~T}_{0}\right)$ (Spectra Count, Packard, USA). Then, the microplates were incubated at $30 \pm 1^{\circ} \mathrm{C}$ for 60 minutes and the absorbances were registered again $\left(\mathrm{T}_{1}\right)$. An additional incubation for 60 minutes at $30 \pm 1^{\circ} \mathrm{C}$ was done and after this period a new spectrophotometric reading was conducted $\left(\mathrm{T}_{2}\right)$. The inhibitory percentage at $\mathrm{T}_{1}$ and $\mathrm{T}_{2}$ was obtained according to the equation $\mathrm{IA}_{\%}=[(C-S) / C] \times 100$, where $\mathrm{IA}_{\%}=$ Inhibitory activity; $C=$ negative control absorbance; $S=$ sample or positive control absorbance (absorbance at time $\mathrm{T}_{1}$ or $\mathrm{T}_{2}$ minus the absorbance at time $\mathrm{T}_{0}$ ).

For samples that reached $\mathrm{IA}_{\%}$ greater than $35 \%$, the above experimental protocol was followed, with modifications (a $500 \mathrm{U} \mathrm{mL}^{-1}$ tyrosinase solution was used, and the absorbances were measured every 10 minutes, up to 1 hour). The quantitative determination was obtained through an analytical curve. For this, the extracts were diluted to concentrations of 100, 80, 40, 20 and $10 \mu \mathrm{gL}^{-1}$ with $25 \%$ DMSO (kojic acid to concentrations of 10, 5, 2.5, 1.25 and $\left.0.625 \mu \mathrm{g} \mathrm{mL}^{-1}\right)$. The analytical curve was plotted between tyrosinase inhibition activity percentages at each time and the concentrations of the extract/positive control. Using the equation of the line, the $\mathrm{IA}_{50}$ was calculated.

\section{Total phenolic and flavonoids content}

The determination of total phenolic content was performed using Folin-Ciocalteu reagent in alkaline medium. Gallic 
acid (Sigma-Aldrich, USA) was used as standard, and its ethanolic solutions (25-700 $\mu \mathrm{g} \mathrm{mL}^{-1}$ ) were used to built-up a standard curve for determining the extracts phenolic content. The extracts were dissolved in ethanol $(10 \mathrm{mg}$ $\left.\mathrm{mL}^{-1}, \mathrm{n}=3\right)$. Aliquots of the samples' solutions $(50 \mu \mathrm{L})$ were mixed in test tubes with $250 \mu \mathrm{L}$ of Folin-Ciocalteu reagent, $500 \mu \mathrm{L}$ of $20 \%$ aqueous sodium carbonate and $4.2 \mathrm{~mL}$ of water. The test tubes were incubated protected from light at room temperature for 30 minutes, and then the absorbances were read at $760 \mathrm{~nm}$ (UV Mini 1240, Shimadzu, Japan). The total phenolic content of the extracts were determined by extrapolation of the analytical curve built-up for the gallic acid standard.

For flavonoids, rutin (Sigma-Aldrich, USA) was used as standard, and its aqueous solutions $(2-30 \mu \mathrm{g} \mathrm{mL}-1)$ were used to built-up a standard curve. The extracts were dissolved in ethanol $\left(10 \mathrm{mg} \mathrm{mL} \mathrm{m}^{-1}, \mathrm{n}=3\right) .2 .5 \mathrm{~mL}$ of the extract solutions were mixed with $1 \mathrm{~mL}$ of chloroform and $1.5 \mathrm{~mL}$ of water and then centrifuged for 3 minutes at $2465 \times \mathrm{g}$ (5810 R, Eppendorf, Germany). The microplates were prepared by adding the following solutions, in this order: $99 \mu \mathrm{L}$ of water; $25 \mu \mathrm{L}$ of $8 \%$ methanolic aluminum chloride hexahydrate solution; $100 \mathrm{~mL}$ of pyridine:methanol $(2: 8, \mathrm{v} / \mathrm{v})$ solution; $6 \mu \mathrm{L}$ of glacial acetic acid; and $20 \mu \mathrm{L}$ of the supernatant of the centrifuged extract (or $20 \mu \mathrm{L}$ of each rutin solution). The plate was stirred for 2 minutes and incubated in the dark for 15 minutes. After incubation, the absorbance was recorded at $405 \mathrm{~nm}$ (Microplate Reader Spectra Count, Packard, USA). The flavonoids content of the extracts were determined by extrapolation of the analytial curve built-up for the rutin standard.

\section{Photoprotection assay}

The extract was incorporated at $15 \%$ in a cosmetic neutral lotion. Two days after that, it was accurately and quickly weighed $\left(1.3 \mathrm{mg} \mathrm{cm}^{-2}\right)$ in poly-methil metacrilate plates $(n=3)$. The plates were then protected from light exposure in a dark chamber at room temperature $\left(\approx 20^{\circ} \mathrm{C}\right)$ for 15 minutes, and after this period they were measured from 290 to $450 \mathrm{~nm}$ at $1 \mathrm{~nm}$ intervals on 9 different sites of each plate by a transmittance analyzer (UV2000S, Labsphere, USA). For UVAPF, the plates were inserted into the UV irradiation source and then exposed to a calculated UV dose. After that, new transmission measurements of the sunscreen samples were conducted for acquisition of the second UV spectrum, and then the final UVAPF, the UVA/UVB Ratio and the Critical Wavelength $(\lambda c)$ were calculated. Detailed protocol and theoretical background can be found in Polonini and colleagues (2013). ${ }^{7}$ All results were expressed as a mean of 27 determinations ( 3 plates, 9 readings each, at different sites).

\section{RESULTS AND DISCUSSION}

The polyphenolic compounds consist of a large group of substances found in all known vegetal species, and the flavonoids are a specific group of compounds within the group of polyphenols. These substances were determined in the extract because they are known to possess strong antioxidant activity, mainly the flavonoids and they also have the capacity to absorb UV radiation and prevent its absorption. The flavonoids specifically mitigate the Reactive oxygen species (ROS) and the penetration of UV rays. ${ }^{8}$ The results of the total phenolic content and the flavonoid content are exposed in Table 1.

\begin{tabular}{|c|c|c|}
\hline $\begin{array}{l}\text { Hydroalcoholic } \\
\text { extract }\end{array}$ & $\begin{array}{l}\text { Total phenolic } \\
\text { content }(\mathrm{g} / 100 \mathrm{~g})^{*}\end{array}$ & $\begin{array}{l}\text { Total flavonoid } \\
\text { content }(\mathrm{g} / 100 \mathrm{~g})^{* *}\end{array}$ \\
\hline Alpinia speciosa & $16.52 \pm 0.07$ & $3.64 \pm 0.82$ \\
\hline
\end{tabular}

"determined as gallic acid;" determined as rutin.

At Table 2, we can see that the antioxidant activity for the hydroalcoholic extract of $A$. speciosa showed a very good result $\left(\mathrm{IC}_{50}=7.13 \mu \mathrm{g} \mathrm{mL}-1\right.$, statistically different from the ascorbic acid standard, $\mathrm{p}<0.05$ ), which can be elucidated by their content of phenolic compounds, such as flavonoids. Phenolic compounds are well known as radical scavengers, metal chelators, reducing agents, hydrogen donors, and singlet oxygen quenchers. A study by Mpalantinos and colleagues ${ }^{9}$ isolated and quantified the flavonoids rutin, kaempferol 3-O-rutinoside, kaempferol 3-O-glucuronide, $(+)$-catechin and (-)-epicatechin from the ethanolic extract of Alpinia speciosa, which may be responsible for this activity. Chompoo and colleagues ${ }^{6}$ evaluated the antioxidant activity of different parts of $A$. speciosa in hydroalcoholic and aqueous extracts. This study showed that not only the total content of phenolic compounds was higher in the aqueous extract, but also the antioxidant activity of aquous extract was superior to hydroalcoholic one, demonstrating the important role of these compounds to the antioxidant activity.

The evaluation of the antioxidant activity is also important when one wants to study the sunscreen potential, because UVA radiation causes its phototoxic effect through the production of free radicals and ROS, which damage DNA, proteins and cell membranes. Introducing exogenous antioxidants in formulations with sunscreening capacity is important because the endogen antioxidants do not always are enough in number or activity to fight against the deleterious effects of the sun, and then this exogenous 


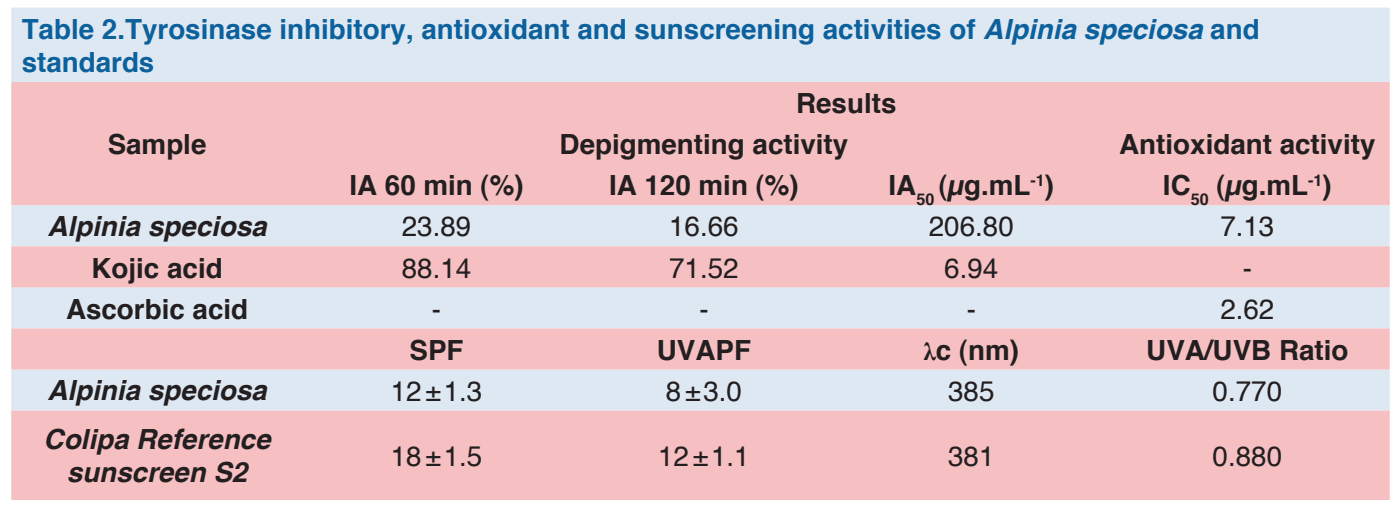

SPF:Sun Protection Factor; UVAPF: UVA Protection Factor.

substances are allies to the natural ones. Analysing the inhibitory activity of tyrosinase (Table 2), we found in the qualitative assay that the capacity of inhibiting tyrosinase remained below $50 \%$, a result which is not satisfactory. Nevertheless, this inhibition was more stable than the standard kojic acid, decreasing approximately $9.0 \%$ in the first hour to second hour of the screening, as opposed kojic acid that reduces its capacity of inhibits tyrosinase in approximately $16.0 \%$.

In the quantitative assay, we observed an $\mathrm{IC}_{50}$ higher than the standard, however the complexity of the extract must be considered, once hydroalcoholic extracts consist of several compounds. Furthermore, the solvent whereby the extract is prepared and the region where the plant was collected significantly affect their final composition. Tyrosinase is a key enzyme for melanogenesis, then its inhibitors may be clinically useful battling against some skin diseases, once melanin has protective functions against skin photocarcinogenesis.

Regarding the photoprotection capacity, the results are shown in Table 3. The extract presented a significant photoprotection for a single UV-filter substance as its SPF, i.e., its protection against UVB sunrays, was equal to 12 (no other UV-filter was added into the formulation but the $A$. speciosa extract, at $15 \%$ ). The extract also presented a relevant UVA protection. This is of great importance, once UVA rays are known to play an important role on skin cancers. Critical Wavelength is another parameter determined to measure the UVA protection, as it defines the spectrum of protection (sunscreens with $\lambda \mathrm{c}$ values near $400 \mathrm{~nm}$ are considered broad spectrum). The US Food and Drug Administration (FDA $)^{10}$ uses this parameter to determine if a product is a broad spectrum sunscreen or not. It considers the broad spectrum test as a pass/fail test based on the critical wavelength value of $370 \mathrm{~nm}$. Under such classification, the extract can be considered a broadspectrum filter.
Table 3: Photoprotection results of Alpinia speciosa hydroalcoholic extract

\begin{tabular}{ccccc}
$\begin{array}{c}\text { Hydroalcoholic } \\
\text { extract }\end{array}$ & SPF & UVAPF & $\lambda \mathbf{c}(\mathrm{nm})$ & $\begin{array}{c}\text { UVAVUVB } \\
\text { Ratio }\end{array}$ \\
$\begin{array}{c}\text { Alpinia speciosa } \\
\text { Colipa Reference } \\
\text { sunscreen S2 }\end{array}$ & $12 \pm 1.3$ & $8 \pm 3.0$ & 385 & 0.770 \\
\hline SPF:SunPros & $12 \pm 1.1$ & 381 & 0.880
\end{tabular}

SPF:Sun Protection Factor; UVAPF:UVA Protection Factor;'Colipa, 2011.

Finally, we have determined the UVA/UVB Ratio, which provides a good idea of which UV region is better blocked by the substances. The value $(0.770)$ shows that the extract has a good UVA/UVB balance.

\section{CONCLUSION}

These data altogether indicate that $A$. speciosa can have application in cosmeceuticals for aesthetics or degenerative diseases, for its great antioxidant, light depigmenting and excellent photoprotection capacities, acting by inhibiting the UV-induced oxidative stress.

\section{ACKNOWLEDGEMENT}

The authors would like to thank the Brazilian agencies CNPq, CAPES and FAPEMIG, for financial support.

\section{CONFLICT OF INTEREST}

The authors declare that there is no Conflict of interest.

\section{ABBREVIATION}

\begin{tabular}{|c|c|}
\hline NUPICS: & $\begin{array}{l}\text { Núcleo de Pesquisa e Inovação } \\
\text { em Ciências da Saúde }\end{array}$ \\
\hline UFJF: & $\begin{array}{l}\text { Universidade Federal de Juiz de } \\
\text { Fora }\end{array}$ \\
\hline ОРPH: & 2,2-diphenyl-1-picrylhydrazyl \\
\hline
\end{tabular}




$\begin{array}{llll}\text { IC: } & \text { Inhibitory activity } & & \text { at time } \mathrm{T}_{0} \text { ) } \\ \mathrm{C}: & \begin{array}{l}\text { absorbance of the negative } \\ \text { control }\end{array} & \text { UV: } & \text { Ultraviolet } \\ \text { S: } & \text { Ubsorbance of the test samples } & \text { UVB: } & \text { Ultraviolet A } \\ \text { DMSO: } & \text { dimethyl sulfoxide } & \text { UVAPF: } & \text { Ultraviolet B } \\ \text { IA } \%: & \text { Inhibitory activity } & & \text { Ultraviolet A Protection } \\ \mathrm{C}: & \text { negative control absorbance } & \text { ROS: } & \text { Factor } \\ \mathrm{S}: & \text { sample or positive control } & \text { US: } & \text { Unitive oxygen species } \\ & \text { absorbance (absorbance at time } & \text { FDA: } & \text { Food and Drug } \\ & \mathrm{T}_{1} \text { or } \mathrm{T}_{2} \text { minus the absorbance } & & \text { Administration }\end{array}$

\section{Highlights of Paper}

- Alpinia speciosa leaves presented antioxidant and sunscreening activity.

- This provide the basis for their use in commercial products.

\section{Author Profile}

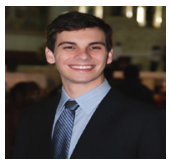

- Dr. Rebeca Mól: Is a Pharmacist graduated at Federal University of Juiz de Fora. She worked as a researcher at the NUPICS research group, with focus in: technological innovation; microbiology; antioxidant and depigmenting assays and evaluation of biological potential of Brazilian plant species. She currently works with the development of new nanostrutured phytoterapic for esporotricosis.

- Dr. Hudson Polonini: Is a pharmacist graduated at Federal University of Juiz de Fora. He has MSc and PhD degrees in Health Sciences. His research interests include the delivery of active pharmaceutical ingredients through alternative routes, as well as analytical chemistry for quality control of pharmaceuticals and the development of new health care products with emphasis in sunscreens.

\section{REFERENCES}

1. Agati G, Tattini M. Multiple functional roles of flavonoids in photo protection. New Phytol. 2010 Jun; 186(4): 786-93.

2. Chompoo J, Upadhyay A, Gima S, Fukuta M, Tawata S. Antiatherogenic properties of acetone extract of Alpinia zerumbet seeds. Molecules 2012 May 25; 17(6): 6237-48.

3. Chompoo J, Upadhyay A, Fukuta M, Tawata S. Effect of Alpinia zerumbet components on antioxidant and skin diseases-related enzymes. BMC Complement Altern Med. 2012 Jul 24; 12(1): 106.

4. de Araújo PF, Coelho-de-Souza AN, Morais SM, Ferreira SC, LealCardoso JH. Antinociceptive effect of the essential oil of Alpinia zerumbet on mice. Phytomed. 2005 Jun; 12(6-7): 482-6.

5. Food and Drug Administration CP, 310 and 352. Sunscreen Drug Products for Over the Counter Human Use; Final Rules and Proposed Rules. Silver Spring; 2011.

6. de Moura RS, Emiliano AF, de Carvalho LC, Souza MA, Guedes DC, Tano T, et al. Antihypertensive and endothelium-dependent vasodilator effects of Alpinia zerumbet, a medicinal plant. $J$ Cardiovasc Pharmacol. 2005 Sep; 46(3): 288-94.

7. Mpalantinos MA, Moura RS, Parente JP, Kuster RM. Biologically Active Flavonoids and Kava Pyrones from the Aqueous Extract of Alpinia zerumbet. Phytother Res. 1998 Sep; 12(6): 442-4.

8. Murakami S, Li W, Matsuura M, Satou T, Hayashi S, Koike K. Composition and seasonal variation of essential oil in Alpinia zerumbet from Okinawa Island. J Nat Med. 2009 Apr; 63(2) 204-8.

9. Polonini HC, Lima LL, Gonçalves KM, do Carmo AM, da Silva AD, Raposo NR. Photoprotective activity of resveratrol analogues. Bioorg Med Chem. 2013 Feb 15; 21(4): 964-8.

10. Santos BA, Roman-Campos D, Carvalho MS, Miranda FM, Carneiro DC, Cavalcante $\mathrm{PH}$, et al. Cardio depressive effect elicited by the essential oil of Alpinia speciosa is related to L-type $\mathrm{Ca}^{2+}$ current blocade. Phytomed. 2011 May 15; 18(7): 539-43. 